\title{
Ballistic Impact Response of Kevlar 49 and Zylon Under Conditions Representing Jet Engine Fan Containment
}

\author{
J. Michael Pereira and Duane M. Revilock \\ NASA Glenn Research Center, Cleveland, Ohio \\ mike.pereira@grc.nasa.gov \\ Duane.M.Revilock@grc.nasa.gov
}

\begin{abstract}
A ballistic impact test program was conducted to provide validation data for the development of numerical models of blade out events in fabric containment systems. The impact response of two different fiber materials - Kevlar 49 (E.I. DuPont Nemours and Company) and Zylon AS (Toyobo Co., Ltd.) was studied by firing metal projectiles into dry woven fabric specimens using a gas gun. The shape, mass, orientation and velocity of the projectile were varied and recorded. In most cases the tests were designed such that the projectile would perforate the specimen, allowing measurement of the energy absorbed by the fabric. The results for both Zylon and Kevlar presented here represent a useful set of data for the purposes of establishing and validating numerical models for predicting the response of fabrics under conditions simulating those of a jet engine blade release situation. In addition some useful empirical observations were made regarding the effects of projectile orientation and the relative performance of the different materials.
\end{abstract}

\section{Introduction}

In the last thirty years the use of aramid fabrics in jet engine blade containment systems has become common. It is recognized that high strength and high elongation fabrics, combined with innovative structural concepts can provide a light weight, effective fan case system that provides the strength required to safely handle impact loads, blade rub loads and the large dynamic loads caused by rotor imbalance. Aramid and other high strength fibers and fabrics have been studied extensively due to their application in a wide range of products such as bullet-proof vests, cut-resistant gloves, tires and sports equipment. However, relatively small amounts of data exist in the public domain for the impact response of fabrics in configurations that are similar to those used in jet engine applications.

Containment design is currently largely based on empirical methods but there is strong motivation on the part of jet engine manufacturers to develop numerical models that can be used to help in the design process of fan containment systems, thereby reducing the cost of testing and increasing confidence and reliability in the design. A number of 
research and commercial computer programs are available that can simulate the impact of a released fan blade on the case (a blade-out event). These are generally transient, explicit integration finite element codes (Livermore Software Technology Corp.; 1998, ABAQUS, Inc., 2003). The codes themselves are accurate and have been validated by years of use but the constitutive, failure and contact models are still the subjects of active research. A large body of data and research studies exist with regard to high strain rate behavior and impact response and constitutive and failure models for metals (Wong and Connors, 1971; Clifton, 2000; Johnson and Cook, 1985). While there is data available in the literature on the impact response of fabrics (Roylance and Wang, 1980; Cunniff, 1996; Figucia, 1980), and models have been developed to simulate fabric impact response (Tabiei and Ivanov, 2002; Lim et al., 2003; Sohdi, 2002) the body of literature is much smaller than for metals. In addition, studies tend to focus on applications other than jet engines (such as body armor) and generally consider impacts by small high velocity projectiles. Jet engine fan containment impact typically involves a larger projectile at sub-sonic velocities.

To address the lack of data and to improve the material models in the range of jet engine applications, a study was recently completed aimed at developing improved computational tools for designing fabric-based engine containment systems (Rajan et al., 2004; Pereira and Revilock, 2004; Simons et al., 2004; Gomuc, 2004). This study was done on Kevlar 49 ${ }^{\circledR}$ and Zylon ${ }^{\circledR}$ as spun (AS) fabric and involved static testing and modeling, ballistic impact testing of fabric rings, material model development and simulation of experiments, and model simulations of ballistic tests, fan blade-out and generic engine modeling

As a follow-up to that work, a second study was conducted with the objective of increasing the confidence and robustness of the material models (Revilock and Pereira, 2008). This involved additional finite element model development and additional static and ballistic impact testing. This paper summarizes the ballistic impact testing that was conducted to provide validation data for the numerical model development. In addition some useful empirical observations were made regarding the effects of projectile orientation and the relative performance of the different materials.

\section{Methods}

The ballistic impact response of fabrics was studied by firing metal projectiles into dry woven fabric specimens using a gas gun. The shape, mass, orientation and velocity of the projectile were varied and recorded. In most cases the tests were designed such that the projectile would perforate the specimen, allowing measurement of the energy absorbed by the fabric.

\section{Materials}

Fabrics woven from two different fiber materials - Kevlar 49 (E.I. DuPont Nemours and Company) and Zylon AS (Toyobo Co., Ltd.) - were tested. The fibers and architecture were selected so that two materials of similar architecture were compared, and two 
different architectures of the same material (Zylon) were compared. The fiber and weave parameters of the materials tested are shown in Table 1 (Simons et al., 2004).

\section{Test Configuration}

The test specimens consisted of layers of 0/90 plain woven cloth, $25 \mathrm{~cm}$ (10 in) wide, wrapped around a ring shaped fixture. The fixture was steel and had an outer diameter of $102 \mathrm{~cm}$ (40 in), a thickness of $2.5 \mathrm{~cm}$ (1 in) and a height the same as the fabric width (25 $\mathrm{cm})$. The fabric was rolled around the fixture under a controlled tension of $25 \mathrm{~N}(5.5 \mathrm{lb})$ to make up the desired number of layers. The fixture had a $25.4 \mathrm{~cm}$ (10 in) circumferential gap at the impact location. It was placed in front of the gun barrel at an incline of $15^{\circ}$ so that the projectile, after exiting the gun barrel, passed over the front edge of the ring, passed through the gap in the ring fixture and impacted the fabric from the general direction of the center of the ring. Because of the circumferential gap, and the tension on the specimen, the fabric was flat at the region where impact occurred, rather than following the curved shape of the ring fixture. This configuration was chosen rather than a flat specimen held in a square or rectangular fixture because experience has shown that in this latter configuration the boundary conditions play a major role in the response of the fabric specimen.

\begin{tabular}{|c|c|c|c|c|}
\hline & & \multicolumn{2}{|c|}{$\begin{array}{c}\text { Zylon AS } \\
\text { Poly- }\end{array}$} & $\begin{array}{c}\text { Kevlar-49 } \\
\text { P-Aramid }\end{array}$ \\
\hline & & Lenzobisoxazol (PBO) & \\
\hline Volume Density & $\left(\mathrm{g} / \mathrm{cm}^{3}\right)$ & 1.54 & 1.54 & 1.44 \\
\hline $\begin{array}{c}\text { Yarn Denier } \\
\text { (measured) [14] }\end{array}$ & $(\mathrm{g} / 9 \mathrm{~km})$ & 500 & 1500 & 1490 \\
\hline Yarn Linear Density & $(\mathrm{mg} / \mathrm{cm})$ & 0.556 & 1.654 & 1.656 \\
\hline Yarn count & $(\mathrm{yarns} / \mathrm{in})$ & $35 \times 35$ & $17 \times 17$ & $17 \times 17$ \\
\hline Yarn count & $(\mathrm{yarns} / \mathrm{cm})$ & $13.8 \times 13.8$ & $6.7 \times 6.7$ & $6.7 \times 6.7$ \\
\hline Fabric ply thickness & $(\mathrm{mm})$ & 0.21 & 0.28 & 0.28 \\
\hline Fabric areal density & $\left(\mathrm{g} / \mathrm{cm}^{2}\right)$ & .01575 & .0223 & .02275 \\
\hline $\begin{array}{c}\text { Degree of Crimp Warp } \\
\text { Yarns }\end{array}$ & $(\%)$ & 3.1 & 2.2 & 1.1 \\
\hline $\begin{array}{c}\text { Degree of Crimp Fill } \\
\text { Yarns }\end{array}$ & $(\%)$ & 0.6 & 0.9 & 0.8 \\
\hline
\end{tabular}

Table 1. Fabric Properties

Three different projectiles were used in this study. The first was a rectangular shaped, $304 \mathrm{~L}$ stainless steel article, $10.2 \mathrm{~cm}$ (4 in) long, $5.1 \mathrm{~cm}(2 \mathrm{in})$ high and $0.8 \mathrm{~cm} \mathrm{(5/16} \mathrm{in)}$ thick (Figure 2), with a nominal mass of $320 \mathrm{gm}$. The front edge and the corners of the projectile were machined with a full radius. This projectile was designated Projectile A. This is the same projectile as was used in an earlier study (Pereira and Revilock, 2004). 
The second projectile was also 304L stainless steel, but had a length of $17.8 \mathrm{~cm}(7 \mathrm{in})$, a height of $3.8 \mathrm{~cm}(1.5 \mathrm{in})$, a thickness of $.60 \mathrm{~cm}(.235 \mathrm{in})$ and the same nominal mass as Projectile A. The front edge and corners also were machined with a full radius (Figure 1). The second projectile was designated Projectile B. The third projectile which was used in only two tests was the same as projectile A, but measured 6 inches in length instead of 4 inches. The third projectile was designated Projectile C.
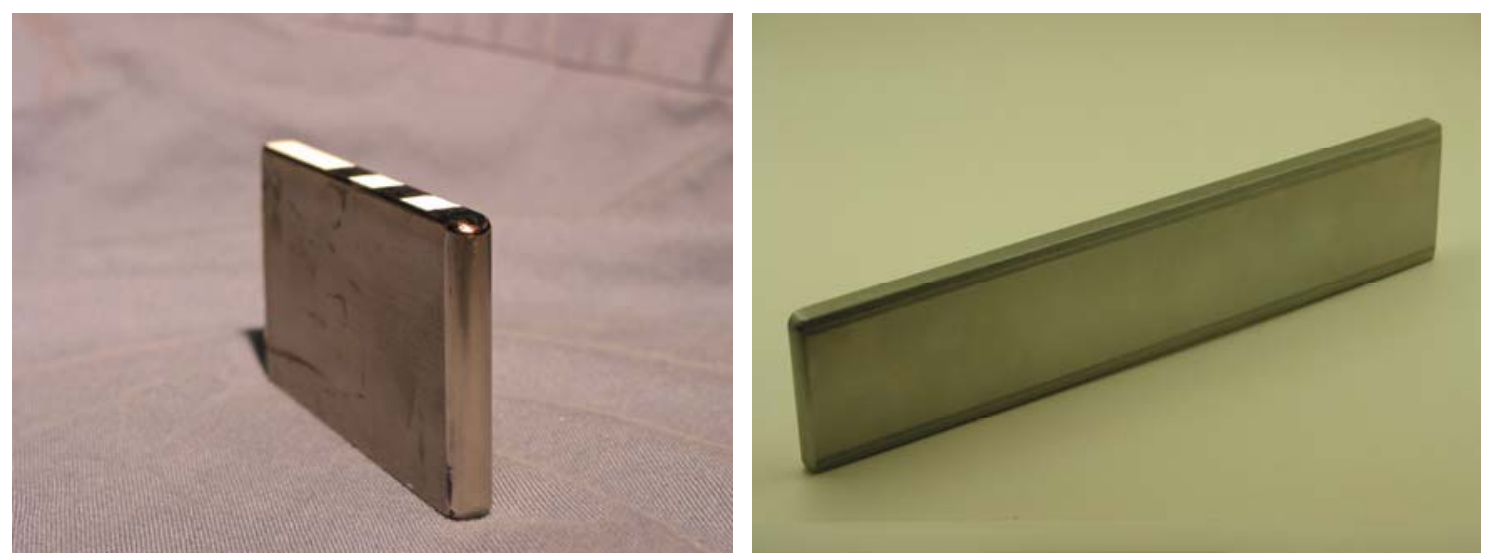

Figure 1. Stainless Steel Projectiles (Left View - Projectile A; Right View - Projectile B)

The impact velocity and exit velocity were measured using high speed digital video cameras. Figure 2 shows sequences of still images obtained from two Phantom 7 cameras (Vision Research, Inc., Wayne, NJ).

The orientation of the projectile was measured from the location of three points on the projectile that defined a local moving coordinate system and three points at a fixed location in the background that defined a laboratory coordinate system. The laboratory coordinate system consisted of the $\mathrm{X}$ axis in the direction of the gun axis, a $\mathrm{Z}$ axis in the vertical upward direction and a $\mathrm{Y}$ axis defined by the vector product of $\mathrm{Z}$ and $\mathrm{X}$. The orientation of the projectile was defined by a set of three Euler angles defined by a rotation $\theta$ (roll), about the laboratory $\mathrm{X}$ axis, followed by a rotation $\psi$ (pitch) about the rotated y-axis, followed by a rotation $\varphi$ (yaw) about the (twice) rotated z-axis. The positions of the points that defined the coordinate systems were measured using a stereo imaging system (PONTOS, GOM mbH) coupled with a pair of calibrated Phantom 5 high-speed digital video cameras (Vision Research, Inc., Wayne, NJ).

\section{Results}

A total of 46 successful impact tests were conducted. A test was considered successful if the velocity before and after impact and the orientation at the impact point could be accurately measured. The amount of energy absorbed by the fabric was highly dependent on the orientation of the projectile at impact. While no correlation was found between 
the roll angle and the energy absorbed, there was a dependency on both pitch and yaw angles. Figure 3 shows the energy absorbed, normalized by the overall fabric specimen areal weight, as a function of the absolute value of the projectile yaw angle. It can be observed that the absorbed energy increases as the absolute value of the yaw angle
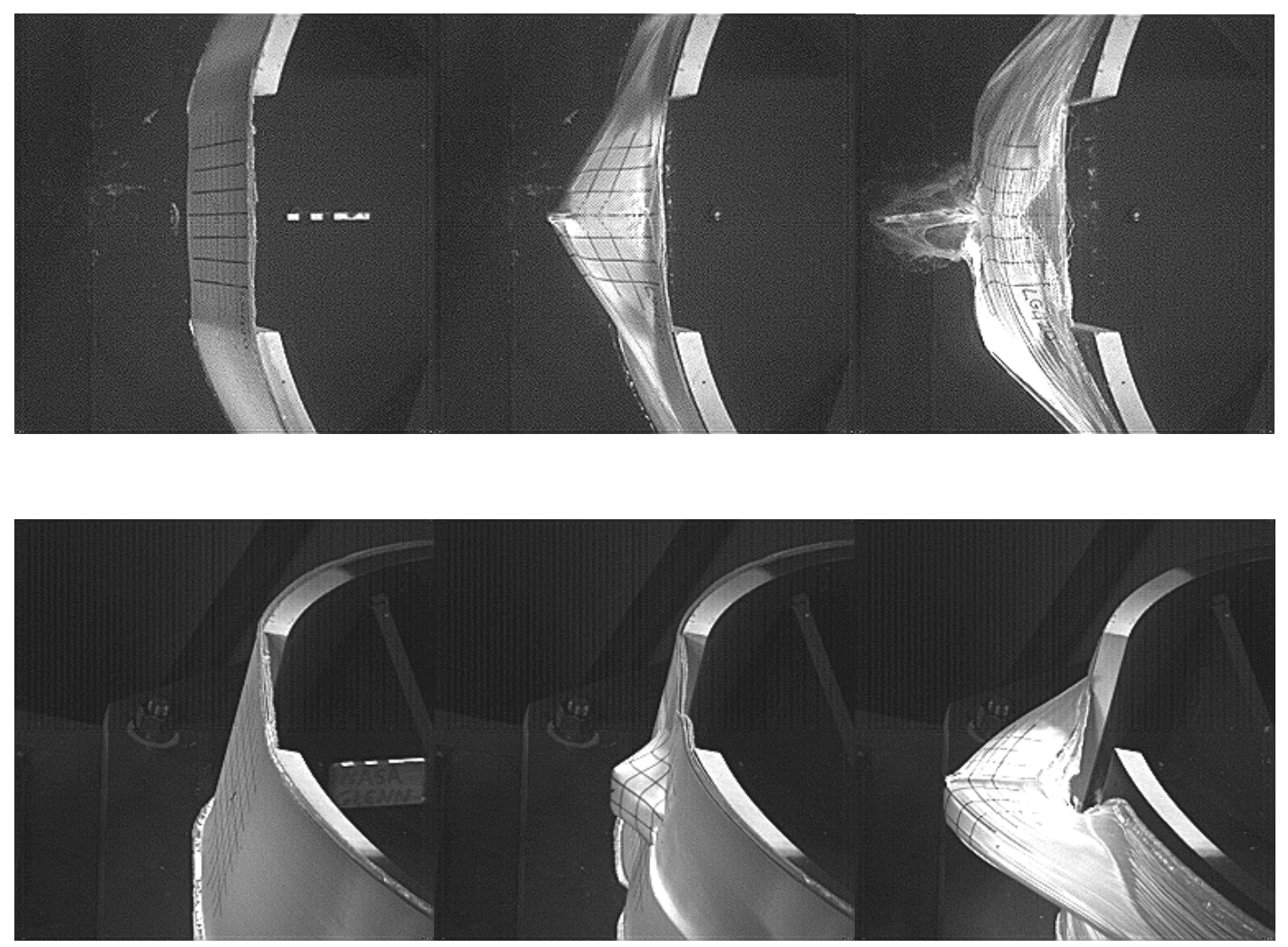

Figure 2. Three Still images from typical tests. Top and Side Views.

increases. The figure shows that the Zylon material absorbs more energy overall, and that as the yaw angle increases the effectiveness of the 500 denier Zylon approaches that of the 1500 denier Zylon. It may be hypothesized that as the yaw angle increases and the projectile appears less sharp, the energy absorption is less localized and the architecture of the fabric plays a less important role. The yaw angle of the projectile has the biggest effect of the three angles on the projected area of the projectile on the fabric.

The effect of the projectile projected area on the energy absorbed, normalized by the total areal weight of the fabric specimen, is shown in Figure 4 for the Kevlar and 1500 denier Zylon. While there is some scatter in the results, there appears to be a linear relationship between the normalized energy absorbed and the projected area of the projectile. In addition, the actual shape of the projectile has less of an effect than the presented area itself. It can also be seen in Figure 4 that the normalized energy absorbed by Zylon is approximately twice as much as that absorbed by Kevlar of the same areal weight and architecture. 


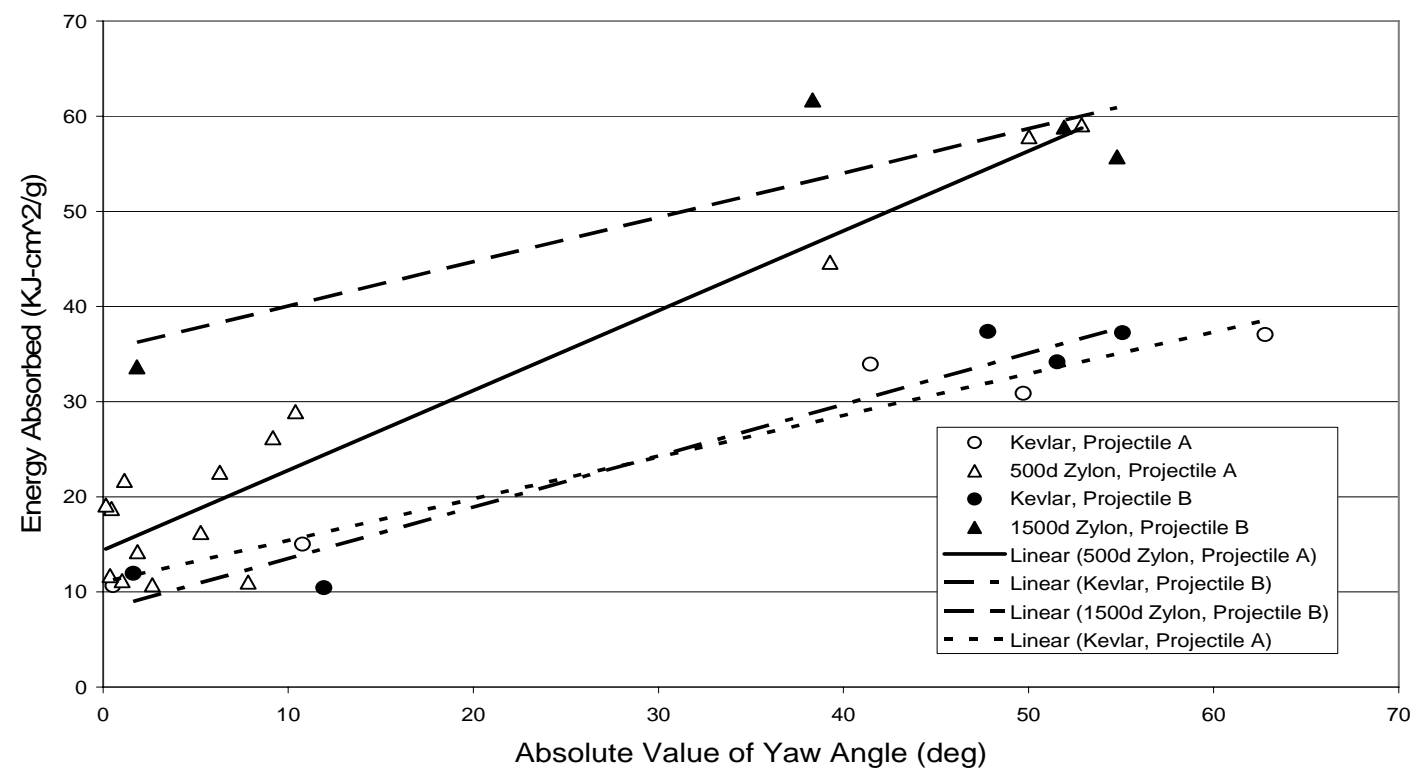

Figure 3. Normalized Absorbed Energy as a Function of the Projectile Yaw Angle

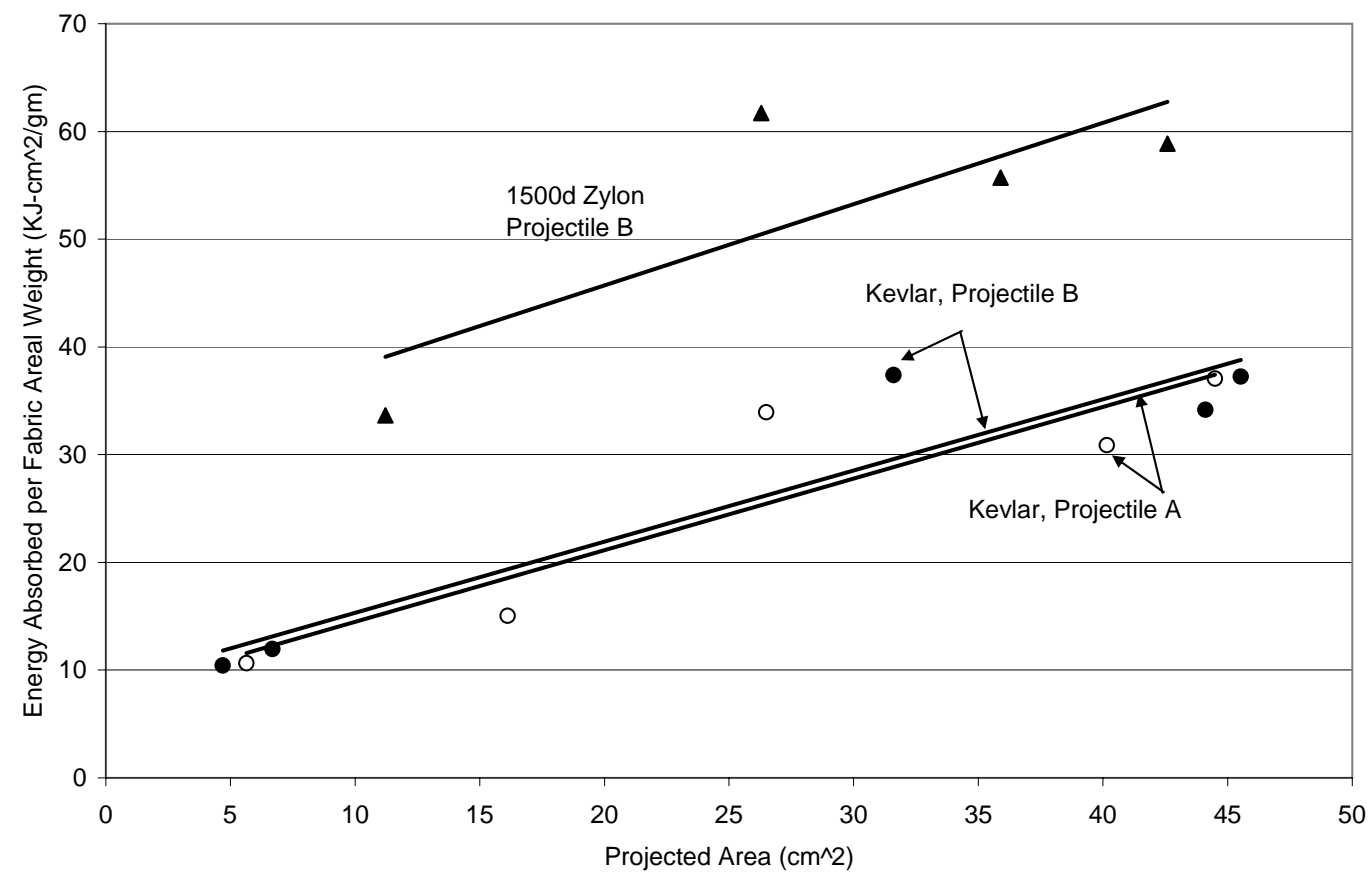

Figure 4 Normalized Absorbed Energy as a Function of the Projectile Projected Area 
One of the objectives of this study was to expand upon results from a previous study for 1500 denier Zylon (Pereira and Revilock, 2004) to verify the enhanced performance over Kevlar. This involved a number of impact tests in which the nominal orientation of the projectile was $(0,0,0)$ pitch, roll and yaw. Figure 5 shows the normalized energy for the 1500 denier Zylon from the two sets of experiments, as well as the earlier results for Kevlar. The material from the present study did not perform as well as that from the earlier study. However, both sets of Zylon absorbed significantly more energy than Kevlar.

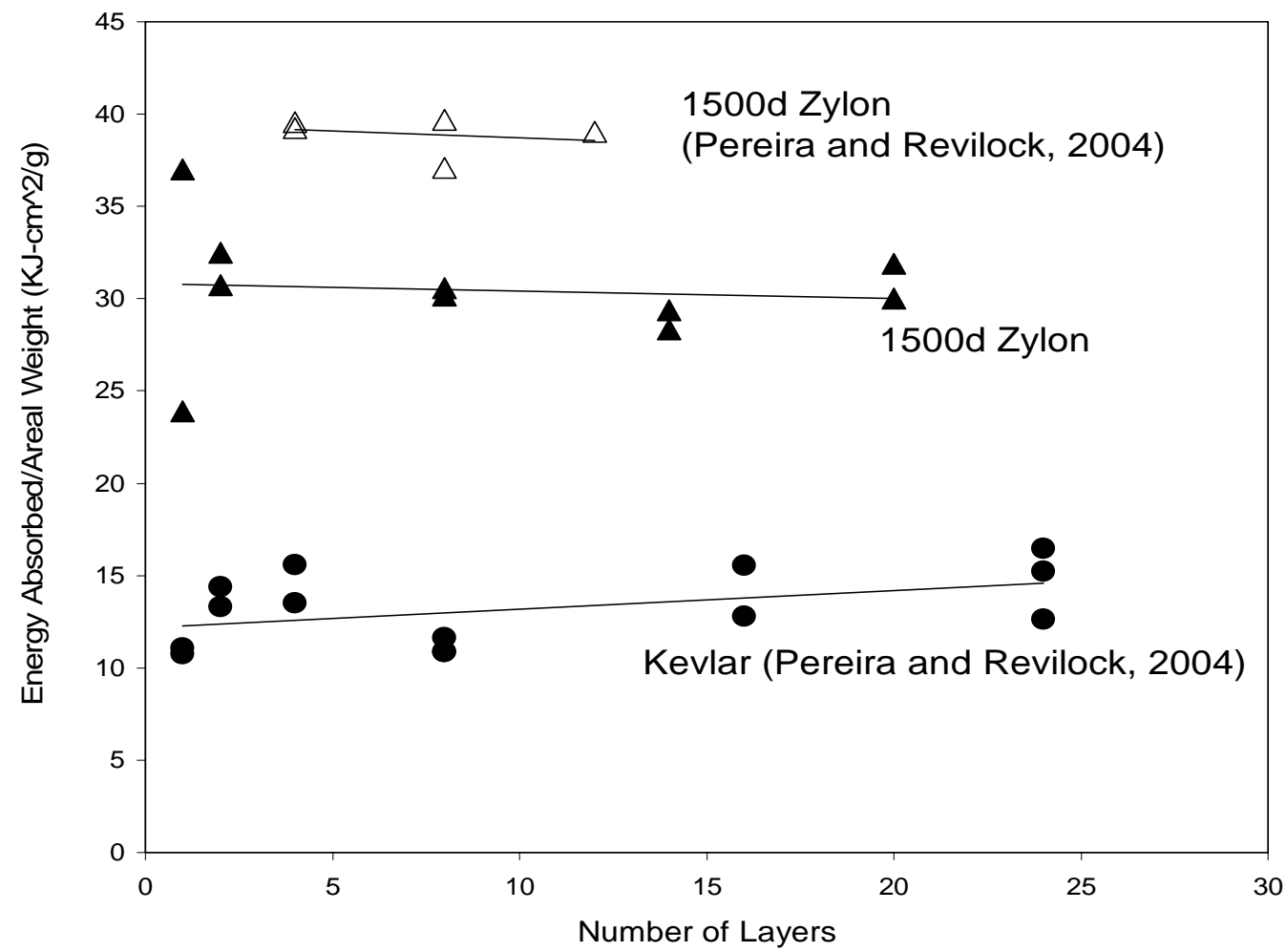

Figure 5. Normalized Energy Absorbed as a Function of the Number of Fabric Layers. Results of This Study Compared With Those of Pereira and Revilock (2004)

The final set of tests was performed to look at the effect of fabric tension. In these tests eight layers of 500d Zylon were wrapped around the fixture with essentially no tension and impacted using projectile A with a desired orientation of $(0,0,0)$ pitch, roll and yaw respectively. The results were compared with the 500d Zylon tests (Projectile A) and are shown in Figure 6. Figure 6 shows the increase in absorbed energy per unit fabric total areal weight as a function of projectile projected area for the specimens under the nominal tension. Results from the two tests at low tension show no significant difference. However, it should be noted that only two tests were conducted at low specimen tension and more tests are needed to gain more confidence in this conclusion. 


\section{Discussion and Conclusions}

The test configuration described here was designed to be somewhat representative of fabric containment systems used in jet engines, while maintaining repeatability and simplicity in the test. The results show that under the conditions of this test, Zylon is able to absorb over twice as much energy as Kevlar when compared on an overall weight basis. The normalized energy absorbed is relatively insensitive to the number of layers of material. These results are consistent with results of those of an earlier study (Pereira and Revilock, 2004). This allows for a fairly simple design procedure if the assumption is made that the amount of energy absorbed per unit weight is independent of the number of layers of material.

Except in cases where the yaw angle was high, the heavier weight Zylon material performed better than the lighter material, for the same overall weight. The energy absorbed by the fabric when normalized by the overall areal weight of the fabric ring is approximately linearly related to the presented area of the projectile at impact and, within the parameters of this study, is independent of the actual shape of the projectile.

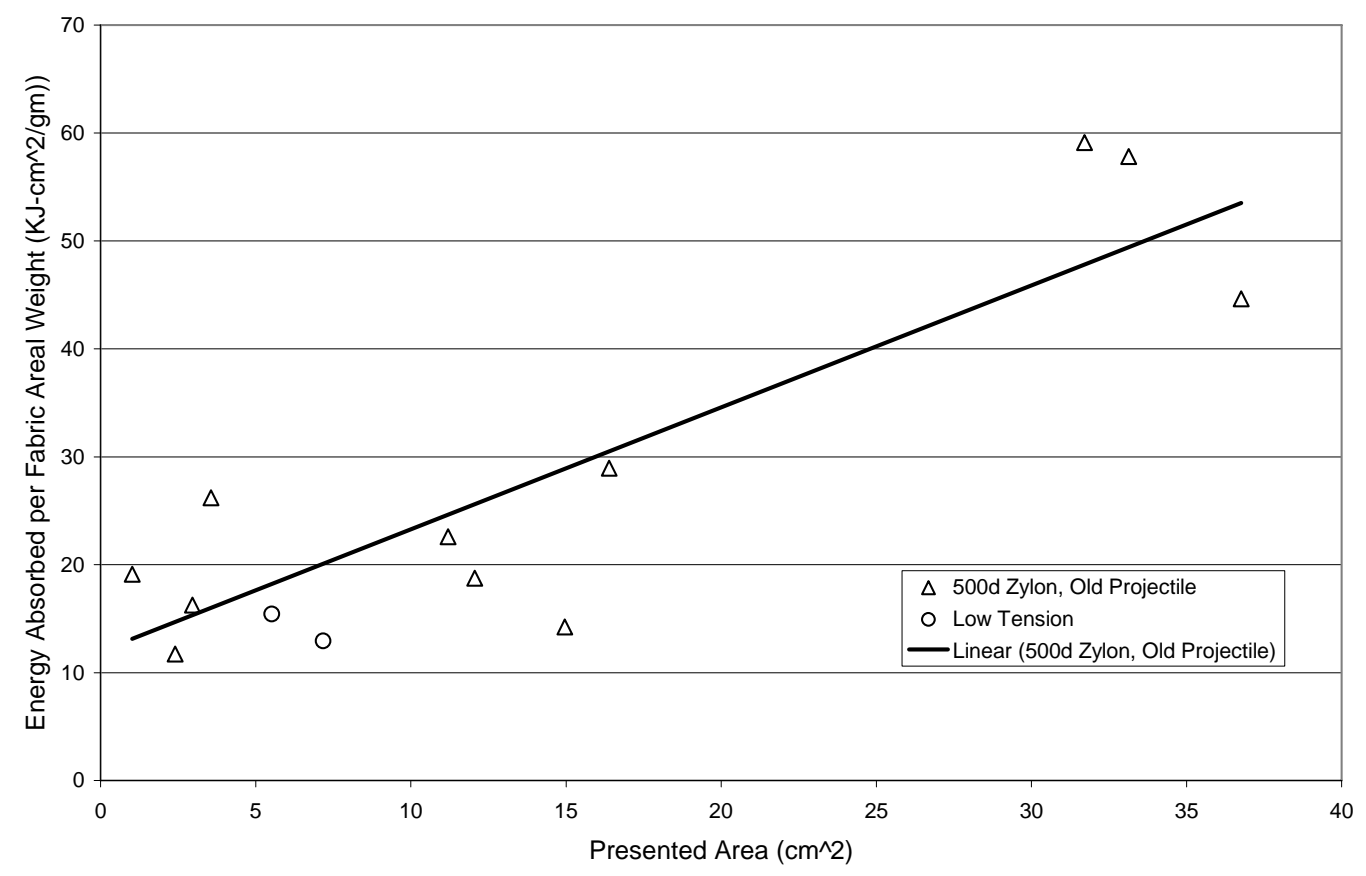

Figure 9. Comparison of Energy Absorbed by Low Tension Specimens and Nominal Tension Specimens

The limited testing performed under conditions of no fabric tension indicate that there is no significant difference in energy absorption between the two tested conditions. However, this should be validated by additional testing. 
The results for both Zylon and Kevlar presented here represent a useful set of data for the purposes of establishing both empirical and numerical models for predicting the response of fabrics under conditions simulating those of a jet engine blade release situations.

\section{References}

ABAQUS, Inc. (2003), ABAQUS/Explicit User's Manual, ABAQUS, Inc., Pawtucket RI, 2003.

Livermore Software Technology Corp (1998), LS-DYNA Theoretical Manual, Livermore CA.

Clifton, R.J. (2000), "Response of Materials Under Dynamic Loading," International Journal of Solids and Structures, Vol, 37, pp. 105-113.

Cunniff, P.M. (1996), "A Semi-empirical Model for the Ballistic Impact Performance of Textile-based Personnel Armor," Textile Research Journal, Vol. 56, pp. 45-60.

Figucia, F. (1980), "Energy Absorption of Kevlar Fabrics Under Ballistic Impact," Technical Report A090390, Defense Technical Information Center.

Gomuc, R. (2004), "Explicit Finite Element Modeling of Multi-layer Composite Fabric for Gas Turbine Engine Containment Systems. Part 4: Model Simulation for Ballistic Tests, Engine Fan Blade-Out and Generic Engine", Final Report, DOT/FAA/AR04/40/P4.

Johnson, G.R. and Cook, W.H. (1985), "Fracture Characteristics of Three Metals Subjected to Various Strains, Strain Rates, Temperatures and Pressures," Engineering Fracture Mechanics, Vol. 21(1), pp. 31-48.

Lim, C.T. , Shim, V.P.W. and Ng, Y.H. (2003), "Finite-element Modeling of the Ballistic Impact of Fabric Armor," International Journal of Impact Engineering, Vol. 28, pp. 1331.

Pereira, J.M., and Revilock, D.M. (2004), "Explicit Finite Element Modeling of Multilayer Composite Fabric for Gas Turbine Engine Containment Systems. Part 2 - Ballistic Impact Testing”, Final Report, DOT/FAA/AR-04/40/P2.

Rajan, S.D., Mobashir, B., Sharda, J., Yanna, V., Deenadaylu, C., Lau, D and Shah, D. (2004), "Explicit Finite Element Modeling of Multi-layer Composite Fabric for Gas Turbine Engine Containment Systems. Part 1 - Static Tests and Modeling", Final Report, DOT/FAA/AR-04/40/P1.

Revilock, D.M. and Pereira, J.M. (2008), "FAA Development of Reliable Modeling Methodologies for Fan Blade Out Containment Analysis Part 2: Ballistic Impact Testing" Final Report to the Federal Aviation Administration, In Press. 
Roylance, D. and Wang, S.S. (1980), Penetration Mechanics of Textile Structures in Ballistic Materials and Penetration Mechanics, R.C. Laible, ed., Elsevier

Simons, J., Erlich, D. and Shockey, D. (2004), "Explicit Finite Element Modeling of Multi-layer Composite Fabric for Gas Turbine Engine Containment Systems. Part 3: Model Development and Simulation of Experiments", Final Report, DOT/FAA/AR04/40/P3.

Tabiei, A. and Ivanov, I. (2002), "Computational Micro-mechanical Model of Flexible Woven Fabric for Finite Element Impact Simulation," International Journal of Numer. Meth., Engng, Vol. 53, pp. 1259-1276.

Wong, A.K and Connors, M.L. (1971), "A Literature Survey on Correlation of Laboratory Tests and the Ballistic Resistance of Rolled Homogeneous Steel and Aluminum Armors," Technical Report AMMRC SP 72-10, Army Materials and Mechanics Research Center, Watertown MA.

Zohdi, T.I. (2002), "Modeling and Simulation of Progressive Penetration of Multilayered Ballistic Fabric Shielding," Comput. Mech. Vol. 29(1), pp. 61-67. 